\title{
Probing the Relationship Between Language Learners' Personality Traits and Their Preferences for Six Category Intervention Analysis: A Focus on Introversion-Extroversion and Sensing-Intuitive Traits
}

\author{
Amir Rakhshan, Massood Yazdani Moghaddam \\ Department of Foreign Languages and Literature, Science and Research Branch, Islamic Azad University, Tehran, Iran
}

\begin{abstract}
The present paper investigates the relationship between Iranian intermediate level EFL (English as a Foreign Language) learners' personality traits and their preferences for Heron's Six Category Intervention Analysis (SCIA). There were 134 Iranian male and female learners participating in this study. A SCIA questionnaire containing 30 items was developed and validated to assess EFL learners' preferences for intervention categories. Moreover, Myers-Briggs Type Indicator (MBTI) was used in the research. Results indicated that whereas in some cases no significant differences were observed, there mostly existed numerous significant differences among language learners with different personality traits and their preferences for SCIA.
\end{abstract}

Keywords: intervention, authoritative, facilitative, personality traits

\section{Introduction}

Language instruction is teeming with instances of direct and indirect intervention. Ellis (as cited in Lengeling, 2011) notes that direct intervention refers to "attempts to actually teach learners specific linguistic properties such as the grammar of the language" (p. 2), whereas indirect intervention refers to the conditions created to facilitate the second language acquisition process. Studies have indicated that mere exposure to linguistic input does not suffice to develop language proficiency (Lantolf \& Throne, 2006; Swain, 2000). The provision of intervention, both of pedagogical and non-pedagogical types, is a dire need for cultivating the process of learning (Heron, 2001; Lai, 2012; Van Compernolle, 2011). In fact, appropriate classroom climate is required to effect positive changes in the classroom conducive to learning (Dörnyei \& Murphey, 2003; Galadja, 2012). Widdowson (1990) states that the classroom is not just the physical surroundings but also considered as a "scene for socio-psychological space" (p. 182). Besides, the results of classroom activities are highly decided by individual differences. Hence, the significance of individual factors in language teaching has exponentially increased (Dornyei, 2005; Dornyei \& Kormos, 2000; MacIntyre \& Gardner, 1989). To cater for individual differences, practitioners should raise their awareness of valid intervention delivery methods.

\footnotetext{
Amir Rakhshan, Ph.D. candidate, Department of Foreign Languages and Literature, Science and Research Branch, Islamic Azad University.

Massood Yazdani Moghaddam, associate professor, Ph.D., South Tehran Branch, Islamic Azad University.
} 


\section{Intervention}

Heron (2001) defined intervention as "an identifiable piece of verbal and/or non-verbal behavior that is a part of the practitioner's service to the client" (p. 3). He contends interventions refer mostly to the practitioner's verbal behavior, and defines Six Category Intervention Analysis (SCIA) as a model that practitioners can use to increase the effectiveness of their communication skills in mentoring relationships and in delivery of intervention (Sloan \& Watson, 2001). There are two categories of SCIA as authoritative and facilitative interventions (Heron, 1976; Maggioli, 2012). Authoritative interventions include (1) prescriptive interventions which "seek to direct the behavior of the patient/colleague, client"; (2) informative interventions which "impart knowledge, information and meaning to the other person"; and (3) confronting interventions which increase clients' awareness "about some limiting attitude or behavior of which s/he is relatively unaware" (Heron, 2001, p. 5). Facilitative interventions, on the other hand, encompass (1) cathartic interventions which "enable the other person to discharge and express painful emotion"; (2) catalytic interventions which attempt to "elicit self-discovery, self-directed learning, and problem solving"; and (3) supportive interventions are the ones which try to "to affirm the worth and value of the other person, their qualities, attitudes, and actions" (Heron, 2001, p. 6).

\section{Personality Traits}

Personality refers to characteristics that account for consistent patterns of feeling, thinking, and behaving. There are different personality types as extroversion-introversion, sensing-intuitive, thinking-feeling, and judging-perceiving (Myers \& Briggs, 1976). According to Eysenck and Chan (1982), an extroverted individual receives energy from outside sources, whereas an introverted person is mostly concerned with the inner world of ideas and is more likely to be involved in solitary activities. Brown (2007) notes that extrovert learners need to receive "ego enhancement, self-esteem, and sense of wholeness from other people", whereas introverted learners "receive that affirmation within oneself" (pp. 166-167). The second category of personality type is sensing and intuitive personality. To Dewaele and Furnham (1999), a sensing person is the one who relies on gathering information through the five senses, usually very unlikely to see the bigger picture and more likely to follow a step-by-step approach (p. 287). On the other hand, an intuitive person is more likely to be drawn by abstract possibilities, and usually draws relationship based on his/her intuition. As the result, they are less interested in factual details (Dornyei, 2005).

Despite the fact that intervention is a highly researched area in Second Language Acquisition (Lai, 2012; Van Compernolle, 2011), the relationships with language learners' personality types and their preferences for SCIA have not been investigated based on Heron's model of SCIA. To redress this lack, this study investigates the relationships between EFL learners' personality traits and their preferences for SCIA. It should be noted that the present study is mostly concerned with the indirect intervention in Ellis's (in Lengeling, 2011) terms, since it tries to probe the verbal/oral language used by instructors based on SCIA and how these appeal to learners with various personality traits. To this end, the following questions are discussed:

(1) Are there any significant differences between language learners' introversion-extroversion traits and their preferences for intervention categories and types?

(2) Are there any significant differences between language learners' sensing-intuitive traits and their preferences for intervention categories and types? 


\section{Method}

The study followed ex-post facto design to gather data from 134 (69 male and 65 female) intermediate level English as a Foreign Language learners' preferences for SCIA and their Personality questionnaires. The participants were studying American English File series at two EFL schools in Tehran, Iran and aged between 15 and 25.

\section{Instrumentation}

Two questionnaires were used in this study. The first questionnaire was a newly developed five point Likert scale questionnaire on the on Six Category Intervention Analysis (Rakhshan, 2015) with 30 items which assessed learners preferences for six types of interventions prescriptive (items 1, 5, 9, 14, and 16), informative (with items of 6, 13, 19, 24, and 30), challenging (items 3, 8, 12, 17, and 28), cathartic (items of 4, 10, 18, 26, and 29), catalytic (items 2, 7, 11, 20, and 21), and supportive (items 5, 22, 23, 25, and 27). Cronbach Alpha produced an alpha 0.83 alpha for this questionnaire. The second instrument was Myers-Briggs Type Indicator (MTBI) (1976) with five-option Likert point scale questions. The questionnaire differentiates respondents on four personality types as (1) introversion-extroversion; (2) sensing-intuitive; (3) thinking-feeling; and (4) judging-perceiving. In this research, however, the results of the first two traits of introversion-extroversion and sensing-intuitive traits are reported. Cronbach Alpha yielded an alpha of 0.90 for these two traits.

\section{Procedure}

The 134 participants took both the newly developed questionnaire (Rakhshan, 2015) and the MTBI questionnaire in a single session of 70 minutes. The questionnaires were in English. The participants answered the questions on coded questionnaires for reasons of anonymity. Also, the participants were assured that their data, representing their names and ages, will not be available to the public.

\section{Data Analysis and Results}

The 134 data were subjected to SPSS to answer the questions of this study. Two separate multivariate analyses of variance (MANOVAs) were run to investigate the differences between language learners' personality traits and their preferences for intervention categories and types. The assumptions required for MANOVA were all met. The results of main effect indicated significant differences between language learners' personality traits and their preferences for Six Category Intervention Analysis, F $(6,127)=6.87, p=.000$, partial $\eta 2=.24$. The index of $\eta$ represents a large effect size so the result of MANOVA is acceptable. In other words, introverted and extroverted language learners' displayed marked differences with regard to their preferences for intervention.

In general, the introverted learners demonstrated higher preferences for intervention categories and types. The results also indicated that the introverted learners $(M=17)$ displayed a significantly higher preference for the prescriptive intervention than extroverted students $(M=14.19), F(1,132)=19.64, p<0.05$, partial $\eta 2$ $=.13$. Furthermore, the introverted learners $(\mathrm{M}=18.1)$ exhibited a significantly higher preference for the informative intervention than extroverted students $(\mathrm{M}=15.50), \mathrm{F}(1,132)=12.75, \mathrm{p}<0.05$, partial $\eta 2=.088$. Also, the introverted learners $(\mathrm{M}=12.24)$ had a significantly higher preference for the challenging intervention than extroverted students $(\mathrm{M}=10.45), \mathrm{F}(1,132)=10.45, \mathrm{p}<0.05$, partial $\eta 2=.044$. Moreover, we found that the introverted learners $(M=19.05)$ showed a significantly higher preference for the cathartic intervention than extroverted students $(M=16.32), F(1,132)=24.37, p<0.05$, partial $\eta 2=.25$. Finally, the introverted learners 
$(\mathrm{M}=21.58)$ indicated a significantly higher preference for the supportive intervention than extroverted students $(\mathrm{M}=19.54), \mathrm{F}(1,132)=7.61, \mathrm{p}<0.05$, partial $\eta 2=.055$. It seems that the introverted learners due to their reflective nature, tend to appreciate receiving interventions. For example, they prefer to be told (prescriptive) what to do (Issac, 2009). Therefore, they can ponder and reflect upon the course of action. Hence, they generally appreciate receiving interventions more than extroverted learners. This is endorsed by Ellis (2008) who believes that introverted learners are more successful at developing cognitive academic language ability which is in line with studies which indicate that introverted learners normally enjoying more academic success may be due to the fact that they spend more time reading and writing.

To answer the second question of this study, another MANOVA was performed on the data. The assumptions required for MANOVA were met for all dependent variables. The results of MANOVA indicated that there was a significant difference between language learners' sensing-intuitive traits and their preferences for intervention categories, $F(6,127)=5.79, p=.000$, partial $\eta 2=.21$. Generally, the intuitive learners demonstrated higher preferences for receiving interventions by the teacher.

The results also revealed that the intuitive learners $(M=17.06)$ displayed a significantly higher preference for the prescriptive intervention than sensing students $(M=14.73), F(1,132)=9.84, p<0.05$, partial $\eta 2=.069$. Furthermore, it was found that the intuitive learners $(M=18.63)$ exhibited a significantly higher preference for the informative intervention than sensing students $(\mathrm{M}=15.80), \mathrm{F}(1,132)=12.58, \mathrm{p}<0.05$, partial $\eta 2=.087$. Also, the intuitive learners $(\mathrm{M}=19.42)$ indicated a significantly higher preference for the cathartic intervention than sensing students $(M=16.74), F(1,132)=17.36, p<0.05$, partial $\eta 2=.11$. Next finding indicated that intuitive learners $(\mathrm{M}=18.12)$ had a significantly higher preference for the catalytic intervention than sensing students $(M=14.61), F(1,132)=24.45, p=.000$, partial $\eta 2=.15$. Finally, the intuitive learners $(M=22.06)$ showed a significantly higher preference for the supportive intervention than sensing students $(M=19.79), F(1$, $132)=7.28, \mathrm{p}<0.05$, partial $\eta 2=.052$. However, no statistically significant differences were observed between sensing and intuitive learners regarding their preferences for confronting (challenging) interventions. This might be due to the learners' negative prior experiences with regard to confronting interventions which might have been delivered by the teacher with regard to timing, depth, or quality of the interventions (Heron, 2001).

\section{Discussion}

The link between introversion-extroversion traits and language learning success in various arenas has been investigated in a number of researches (Kiany, 1997; Swain \& Burnaby, 1976). The present study indicated that introverted language learners showed significantly marked preferences for receiving the following interventions than their extroverted counterparts, based on the order of their magnitude: (1) cathartic; (2) prescriptive; (3) informative; (4) challenging; and (5) supportive. In case of catalytic interventions, however, introverted and extroverted language learners did not demonstrate any significant differences. The reason is probably the unwillingness of introverted learners to respond when the preparation time is limited, i.e., for catalytic interventions where the learners are required to provide an immediate answer, introverted learners, due to their lower willingness to communicate, did not show any differences when compared with extroverted learners.

Furthermore, the results revealed that there were significant differences between language learners' sensing-intuitive traits and their preferences for intervention categories. The intuitive learners indicated generally higher preferences for receiving intervention. Specifically, these preferences were different in case of 
the following interventions based on their magnitude: (1) catalytic; (2) cathartic; (3) informative; (4) prescriptive; and (5) supportive. However, no significant differences were observed between sensing and intuitive language learners with regard to their preferences for challenging (confronting) interventions. The reason is that probably neither sensing nor intuitive learners would like to have their dignity lost in the classroom setting because of poor delivery of confronting interventions. In addition, what Heron (2001) calls degenerate interventions, may create anxiety which distorts behavior, and hence be considered not appealing to the language learners.

The result of this study can be discussed in the light of sociocultural theory. Ellis (1999) notes that within sociocultural approach towards second language acquisition "interaction is the actual site of learning" (p. 21). The role of environment has been frequently highlighted in the Second Language Acquisition theories as Chaos Complexity theory (Larsen-Freeman, 1997; Larsen-Freeman \& Cameron, 2008), Dynamic System (de Bot, Lowie, \& Verspoor, 2007), and Dynamic assessment (Vygotsky, 1986). In addition, meticulous catering for the nature and quality of the intervention and interaction in the classroom, i.e., the actual words and the classroom language which teachers decide to employ while managing such interactions, can be facilitated through conscious and proper use of SCIA model.

\section{Conclusion}

Provision of a learning atmosphere conducive to learning is a great step; language teachers can take to aid language learners to overcome the affective obstacles in the learning process. To achieve this aim, it is suggested that teachers attempt to raise their awareness of various indirect interventions while dealing with language learners. In addition, gearing these valid interventions to the learners' individual differences can help teachers achieve long-term success in their profession.

\section{References}

Brown, H. D. (2007). Principles of language learning and teaching (5th ed.). San Francisco: Longman.

de Bot, K., Lowie, W., \& Verspoor, M. (2005). Second language acquisition: An advanced resource book. USA: Routledge.

Dewaele, J., \& Furnham, A. (1999). Extraversion: The unloved variable in applied linguistic research. Language Learning, 49, 283-298.

Dornyei, Z. (2005). The psychology of the language learner: Individual differences in second language acquisition. Mahwah, NJ: Lawrence Erlbaum.

Dörnyei, Z., \& Kormos, J. (2000). The role of individual and social variables in oral task performance. Language Teaching Research, 4, 275-300.

Dörnyei, Z., \& Murphey, T. (2003). Group dynamics in the language classroom. Cambridge: Cambridge University Press.

Ellis, R. (1999). (Ed.). Learning a second language through interaction. Philadeliphia: John Benjamins.

Ellis, R. (2008). The study of second language acquisition (2nd ed.). Oxford: Oxford University Press.

Eysenck, S., \& Chan, J. (1982). A comparative study of personality in adults and children: Hong Kong vs. England. Personality and individual differences, 3, 153-60.

Galadja, D. (2012). Teacher's zone of action in facilitating group dynamics. Lingvarm Arena, 3, 89-101.

Heron, J. (1976). A six-category intervention analysis. British Journal of Guidance \& Counseling, 4(2), 143-55.

Heron, J. (2001). Helping the client: A creative practical guide (5th ed.). London: Sage Publication.

Issac, T. (2009). Introverted students in the classroom: How to bring out their best. Faculty Focus. Retrieved from http://www.facultyfocus.com/articles/teaching-and-learning/introverted-students-in-the-classroom-how-to-bring-out-their-be st

Kiany, G. (1997). Extraversion and pedagogical setting as sources of variation in different aspects of English proficiency (Unpublished doctoral dissertation, University of Essex, United Kingdom). 
Lai, W. (2012). Concept-based foreign language pedagogy: Teaching the Chinese temporal system (Unpublished Ph.D. dissertation, The Pennsylvania State University, University Park, PA).

Lantolf, J. P., \& Throne, S. L. (2006). Sociocultural theory and the genesis of second language development. Oxford: Oxford University Press.

Larsen-Freeman, D. (1997). Chaos/complexity science and second language acquisition. Applied Linguistics, 18(2), 141-165.

Larsen-Freeman, D., \& Cameron, L. (2008). Complex systems and applied linguistics. Oxford: OUP.

Lengeling, M. M. (2011). Past, present, and future of second language acquisition: An interview with Rod Ellis. Mextesol Journal, 35(1), 1-7.

MacIntyre, P., \& Gardner, R. (1989). Anxiety and second language learning: Toward a theoretical clarification. Language Learning, 39, 251-275.

Maggioli, G. E. (2012). Teaching language teachers: Scaffolding professional learning. Rowman and Littlefield: UK.

Myers, I., \& Briggs, K. (1976). The Myers-Briggs type indicator: Form G. Pablo Alto, California: Consulting Psychology Press.

Rakhshan, A. (2015). Developing a six category intervention analysis (SCIA) questionnaire: A classroom language version. Manuscript submitted for publication.

Sloan, G., \& Watson, H. (2001). John Heron's six category intervention analysis: Towards understanding interpersonal relations and progressing the delivery of clinical supervision for mental health nursing in the United Kingdom. Journal of Advanced Nursing, 36(2), 206-214.

Swain, M. (2000). The output hypotheses and beyond: Mediating acquisition through collaborative dialogue. In J. P. Lantolf (Ed.), Sociocultural theory and second language learning (pp. 97-114). Oxford: Oxford University Press.

Swain, M., \& Burnaby, B. (1976). Personality characteristics and second language learning in young children. Working Papers on Bilingualism, 11, 115-128.

Van Compernolle, R. A. (2011). Developing second language sociopragmatic knowledge through concept-based instruction: A mictrogenetic case study. Journal of pragmatics, 43, 3268-3283. doi:10.1016/j.pragma.2011.06.009

Vygotsky, L. S. (1986). Thought and language. Cambridge, MA: MIT Press.

Widdowson, H. G. (1990). Aspects of language teaching. Oxford: OUP. 